\title{
Article
}

\section{In Vitro Neurotoxicity of Chinese Krait (Bungarus multicinctus) Venom and Neutralization by Antivenoms}

\author{
Qing Liang ${ }^{1,2}$, Tam Minh Huynh ${ }^{1}$, Yen Zhi Ng ${ }^{1}$, Geoffrey K. Isbister ${ }^{1,3}{ }^{\mathbb{D}}$ and Wayne C. Hodgson ${ }^{1, * \mathbb{D}}$ \\ 1 Monash Venom Group, Department of Pharmacology, Biomedical Discovery Institute, Monash University, \\ Clayton, VIC 3800, Australia; qing.liang@monash.edu (Q.L.); Tommy.Huynh@monash.edu (T.M.H.); \\ yzng5@student.monash.edu (Y.Z.N.); geoff.isbister@gmail.com (G.K.I.) \\ 2 Department of Emergency Medicine, The First Affiliated Hospital of Guangzhou Medical University, \\ 151 Yanjiang Rd, Guangzhou 510120, China \\ 3 Clinical Toxicology Research Group, University of Newcastle, Newcastle, NSW 2308, Australia \\ * Correspondence: wayne.hodgson@monash.edu
}

Citation: Liang, Q.; Huynh, T.M.; Ng Y.Z.; Isbister, G.K.; Hodgson, W.C. In Vitro Neurotoxicity of Chinese Krait (Bungarus multicinctus) Venom and Neutralization by Antivenoms. Toxins 2021, 13, 49. https://doi.org/ $10.3390 /$ toxins 13010049

Received: 15 December 2020 Accepted: 6 January 2021 Published: 11 January 2021

Publisher's Note: MDPI stays neutral with regard to jurisdictional clai$\mathrm{ms}$ in published maps and institutional affiliations.

Copyright: (C) 2021 by the authors. Licensee MDPI, Basel, Switzerland. This article is an open access article distributed under the terms and conditions of the Creative Commons Attribution (CC BY) license (https:// creativecommons.org/licenses/by/ $4.0 /)$.

\begin{abstract}
Bungarus multicinctus, the Chinese krait, is a highly venomous elapid snake which causes considerable morbidity and mortality in southern China. B. multicinctus venom contains pre-synaptic PLA $_{2}$ neurotoxins (i.e., $\beta$-bungarotoxins) and post-synaptic neurotoxins (i.e., $\alpha$-bungarotoxins). We examined the in vitro neurotoxicity of B. multicinctus venom, and the efficacy of specific monovalent Chinese B. multicinctus antivenom, and Australian polyvalent elapid snake antivenom, against venom-induced neurotoxicity. B. multicinctus venom $(1-10 \mu \mathrm{g} / \mathrm{mL})$ abolished indirect twitches in the chick biventer cervicis nerve-muscle preparation as well as attenuating contractile responses to exogenous $\mathrm{ACh}$ and $\mathrm{CCh}$, but not $\mathrm{KCl}$. This indicates a post-synaptic neurotoxic action but myotoxicity was not evident. Given that post-synaptic $\alpha$-neurotoxins have a more rapid onset than pre-synaptic neurotoxins, the activity of the latter in the whole venom will be masked. The prior addition of Chinese B. multicinctus antivenom $(12 \mathrm{U} / \mathrm{mL})$ or Australian polyvalent snake antivenom $(15 \mathrm{U} / \mathrm{mL})$, markedly attenuated the neurotoxic actions of $B$. multicinctus venom $(3 \mu \mathrm{g} / \mathrm{mL})$ and prevented the inhibition of contractile responses to ACh and CCh. The addition of B. multicinctus antivenom $(60 \mathrm{U} / \mathrm{mL})$, or Australian polyvalent snake antivenom $(50 \mathrm{U} / \mathrm{mL})$, at the $t_{90}$ time point after the addition of B. multicinctus venom $(3 \mu \mathrm{g} / \mathrm{mL})$, did not restore the twitch height over $180 \mathrm{~min}$. The earlier addition of $B$. multicinctus antivenom $(60 \mathrm{U} / \mathrm{mL})$, at the $t_{20}$ or $t_{50}$ time points, also failed to prevent the neurotoxic effects of the venom but did delay the time to abolish twitches based on a comparison of $t_{90}$ values. Repeated washing of the preparation with physiological salt solution, commencing at the $t_{20}$ time point, failed to reverse the neurotoxic effects of venom or delay the time to abolish twitches. This study showed that B. multicinctus venom displays marked in vitro neurotoxicity in a skeletal muscle preparation which is not reversed by antivenom. This does not appear to be related to antivenom efficacy, but due to the irreversible/pseudo-irreversible nature of the neurotoxins.
\end{abstract}

Keywords: Bungarus multicinctus; neurotoxicity; envenoming; venom; antivenom; snake

Key Contribution: This manuscript confirms the efficacy of $B$. multicinctus antivenom against the in vitro neurotoxic effects of B. multicinctus venom. However, once established, the neurotoxic effects are difficult to reverse due to the properties of the neurotoxins contributing to this activity.

\section{Introduction}

Bungarus genus (kraits) are nocturnal venomous snakes from the Elapidae family that are only found in Asia with widespread distribution across many countries including India, Pakistan, Indonesia, Sri Lanka, Malaysia, Bangladesh, Vietnam and China. Kraits are recognized by their banded pattern and possess venoms that contain highly potent neurotoxins. Three species of Bungarus are found in China: Bungarus multicinctus (Chinese 
krait or many-banded krait), Bungarus fasciatus (banded krait) and Bungarus bungaroides (Himalayan krait) [1]. In China, B. multicinctus and B. fasciatus are more medically important because they are more common and, therefore, more likely to cause envenoming in humans. Although robust epidemiological data is lacking, it has been estimated that B. multicinctus bites account for approximately $8 \%$ of all snakebites in China, while B. fasciatus bites account for $2.3 \%$ [2].

B. multicinctus is widely distributed in southern China [1], as well as in Myanmar, north Vietnam, Laos and Thailand [3]. Although B. multicinctus bites are ranked as the fifth most common in China, B. multicinctus envenoming is ranked first for case fatality rates, ranging from 26.9-33.3\% depending on geographical location [2]. The hallmark of B. multicinctus envenoming is progressive neuromuscular paralysis requiring prolonged artificial ventilation but with minimal local swelling and pain at the bite site [2,4-6]. B. multicinctus venom contains a large proportion of post-synaptic "three finger" toxins (3-FTx) (i.e., $\alpha$-bungarotoxins) and pre-synaptic phospholipase $\mathrm{A}_{2}\left(\mathrm{PLA}_{2}\right) \beta$-bungarotoxins $[7,8]$. Proteomic data indicates that PLA 2 and 3-FTx toxins represent the most abundant components in Chinese B. multicinctus venom, at $66.4 \%$ and $32.6 \%$, respectively [9].

Patients envenomed by $B$. multicinctus develop respiratory failure in spite of early (i.e., within $4 \mathrm{~h}$ of the bite) administration of the recommended quantities of $B$. multicinctus antivenom [5]. It is believed that this clinical manifestation of B. multicinctus envenoming (i.e., antivenom resistant neurotoxicity) is primarily due to rapid fixation and irreversible necrotic degeneration of the nerve terminal boutons by the PLA $2 \beta$-bungarotoxins [10-13]. Contributing to this effect, the post-synaptic neurotoxins from $B$. multicinctus venom are relatively irreversible long-chain $\alpha$-neurotoxins $[10,14]$. However, antivenom 'effectiveness' is primarily evaluated in vivo by testing the ability of antivenom to prevent death in a rodent model. We have previously reported discrepancies between rodent lethality-based efficacy studies and in vitro neuromuscular preparation studies for two Malaysian Krait Species (Bungarus candidus and Bungarus fasciatus) [15].

The efficacy of Chinese $B$. multicinctus antivenom against neurotoxicity has not previously been examined in vitro. In the current study, the in vitro neurotoxic activity of Chinese $B$. multicinctus venom was assessed in the chick biventer cervicis nerve-muscle preparation. The neutralizing efficacy of the Chinese monovalent B. multicinctus antivenom, and the Australian polyvalent snake antivenom, against Chinese B. multicinctus venom was assessed. In addition, the ability of the Chinese $B$. multicinctus antivenom to reverse neurotoxicity at various time points post-venom was also evaluated.

\section{Results}

2.1. In Vitro Neurotoxicity

2.1.1. Concentration-Dependent Inhibition of Twitches and Exogenous Agonists Responses

B. multicinctus venom $(1-10 \mu \mathrm{g} / \mathrm{mL})$ caused concentration-dependent inhibition of indirect twitches in the chick biventer preparation when compared to vehicle $(n=6$; one-way ANOVA, $p<0.05$; Figure 1a). T90 values (i.e., time to cause $90 \%$ inhibition of twitches) for $B$. multicinctus venom were: $1 \mu \mathrm{g} / \mathrm{mL}, 35 \pm 3 \mathrm{~min} ; 3 \mu \mathrm{g} / \mathrm{mL}, 28 \pm 2 \mathrm{~min}$; and $10 \mu \mathrm{g} / \mathrm{mL}, 16 \pm 1 \mathrm{~min}$. B. multicinctus venom $(1-10 \mu \mathrm{g} / \mathrm{mL})$ abolished contractile responses to exogenous $\mathrm{ACh}(1 \mathrm{mM}), \mathrm{CCh}(20 \mu \mathrm{M})$, but not responses to $\mathrm{KCl}(40 \mathrm{mM})$, indicating an action at the post-synaptic nerve terminal but no myotoxicity (Figure 1b).

\subsubsection{Prevention of In Vitro Neurotoxicity with Antivenom}

The prior addition of Chinese $B$. multicinctus antivenom $(12 \mathrm{U} / \mathrm{mL}, 2 \times$ the recommended titer), or Australian polyvalent snake antivenom $(15 \mathrm{U} / \mathrm{mL}, 50 \times$ the recommended titer), markedly attenuated the neurotoxic actions of B. multicinctus venom $(3 \mu \mathrm{g} / \mathrm{mL})$ (Figure $2 \mathrm{a}, \mathrm{c}$ ) and prevented the inhibition of contractile responses to $\mathrm{ACh}$ and $\mathrm{CCh}$ (Figure 2b,d). 
(a)

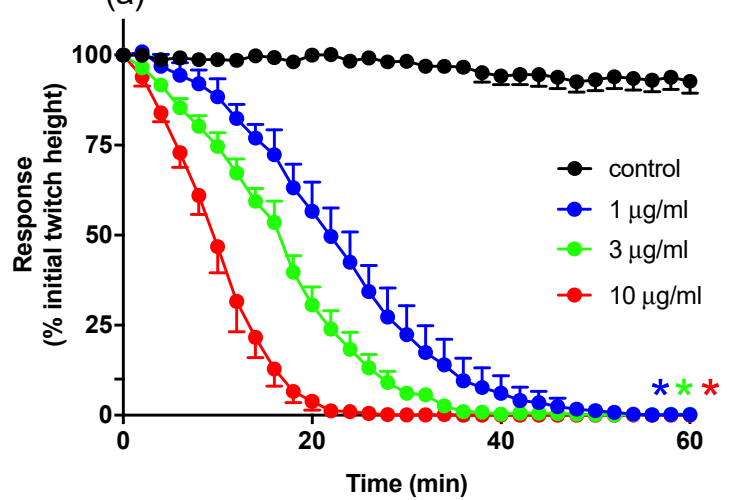

(b)

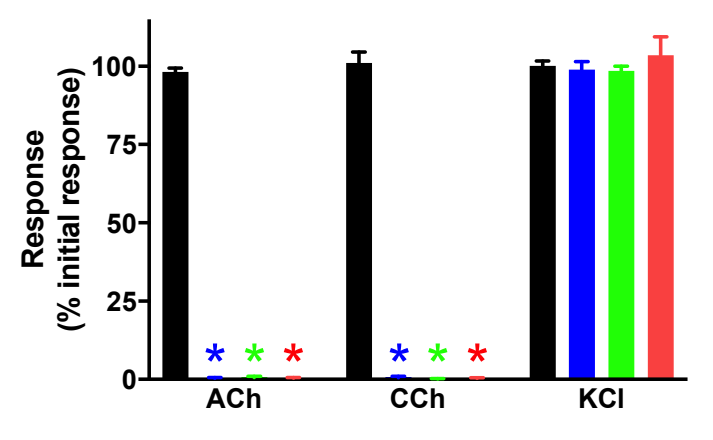

Figure 1. The concentration-dependent in vitro neurotoxic effects of $B$. multicinctus venom $(1-10 \mu \mathrm{g} / \mathrm{mL})$ on (a) indirect twitches and (b) responses to exogenous agonists acetylcholine (ACh; $1 \mathrm{mM})$, carbachol $(\mathrm{CCh} ; 20 \mu \mathrm{M})$ and potassium chloride $(\mathrm{KCl} ; 40 \mathrm{mM})$ in the chick biventer cervicis nerve-muscle preparation. ${ }^{*} p<0.05$, significantly different from (a) control at $60 \mathrm{~min}$ or (b) pre-venom response to same agonist, $n=6$.

(a)

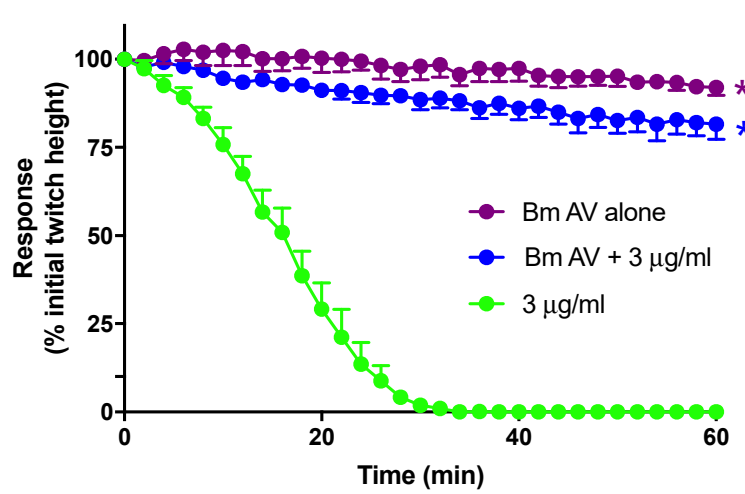

(c)

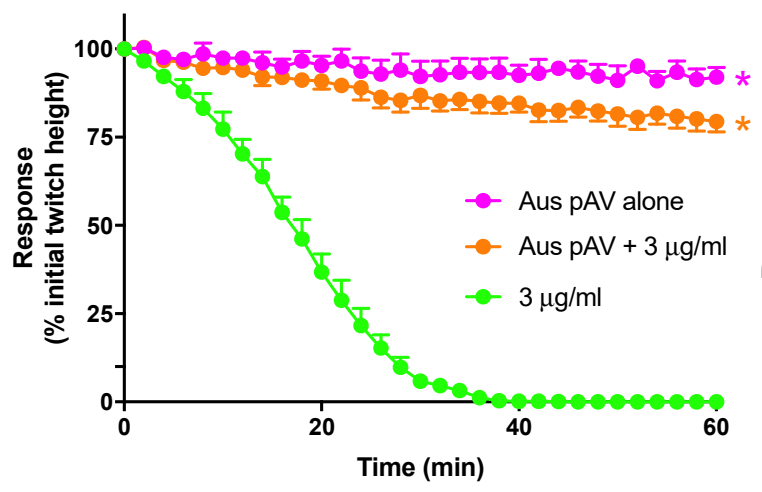

(b)

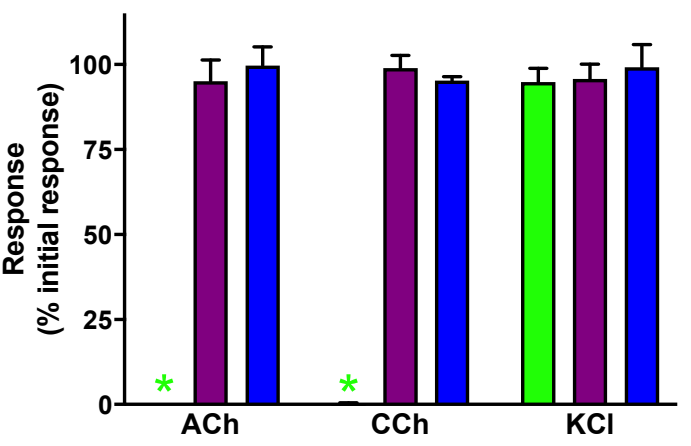

(d)

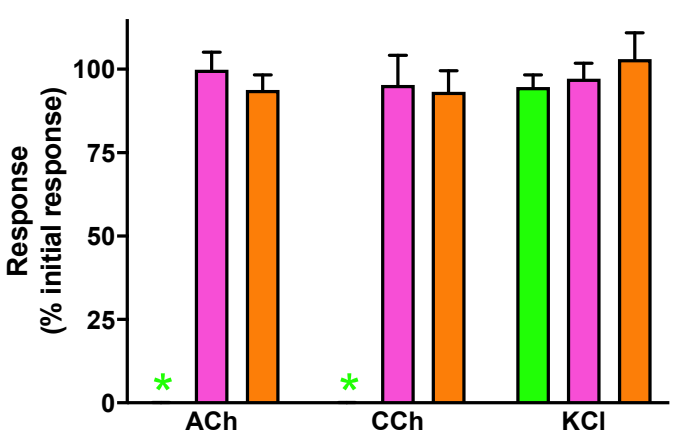

Figure 2. The effect of pre-addition of $(\mathbf{a}, \mathbf{b})$ Chinese B. multicinctus antivenom (Bm AV; $12 \mathrm{U} / \mathrm{mL})$ or $(\mathbf{c}, \mathbf{d})$ Australian polyvalent antivenom (Aus pAV; $15 \mathrm{U} / \mathrm{mL}$ ) on the neurotoxicity of $B$. multicinctus venom $(3 \mu \mathrm{g} / \mathrm{mL})$. Panels $(\mathbf{a}, \mathbf{c})$ show the effects on indirect twitches and panels $(\mathbf{b}, \mathbf{d})$ show the effects on responses to acetylcholine (ACh; $1 \mathrm{mM})$, carbachol $(\mathrm{CCh} ; 20 \mu \mathrm{M})$ and potassium chloride $(\mathrm{KCl} ; 40 \mathrm{mM})$, in the chick biventer cervicis nerve-muscle preparation. ${ }^{*} p<0.05$, significantly different compared to venom in the absence of antivenom at $60 \mathrm{~min}(\mathbf{a}, \mathbf{c})$ or compared to pre-venom response to same agonist $(\mathbf{b}, \mathbf{d}) . n=5-6$.

\subsubsection{Reversal of In Vitro Neurotoxicity with Antivenom and Washings}

The addition of Chinese B. multicinctus antivenom $(60 \mathrm{U} / \mathrm{mL}, 10 \times$ the recommended titer), at the $t_{90}$ time point after the addition of B. multicinctus venom $(3 \mu \mathrm{g} / \mathrm{mL})$, did not 
restore twitch height (Figure 3a), but significantly reversed the venom-induced inhibition of responses to $\mathrm{ACh}(38 \pm 8 \%$ of initial response) while having no significant effect on the response to $\mathrm{CCh}$ and $\mathrm{KCl}$ (Figure $3 \mathrm{~b}$ ).
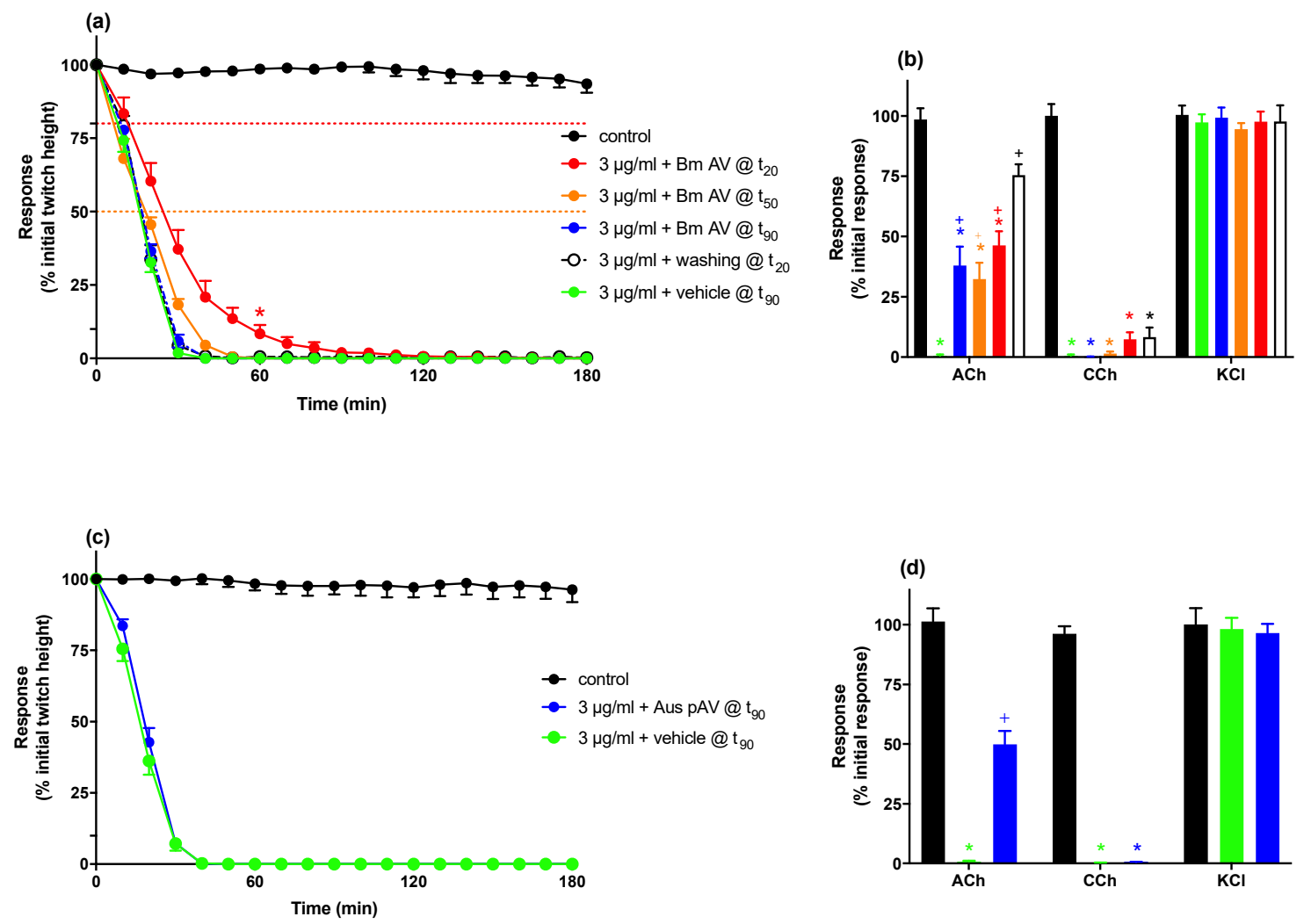

Figure 3. The effect of the addition of Chinese B. multicinctus antivenom $\left(\mathrm{Bm} \mathrm{AV;60} \mathrm{U/mL)}\right.$ at the $t_{20} / t_{50} / t_{90}$ time points or repeatedly washing at the $t_{20}$, on $B$. multicinctus venom $(3 \mu \mathrm{g} / \mathrm{mL})$ neurotoxicity. Panel (a) shows the effects on indirect twitches and panel (b) shows the effects on responses to acetylcholine (ACh; $1 \mathrm{mM})$, carbachol $(\mathrm{CCh} ; 20 \mu \mathrm{M})$ and potassium chloride $(\mathrm{KCl} ; 40 \mathrm{mM})$, in the chick biventer cervicis nerve-muscle preparation. $n=6$. The effect of the addition of Australian polyvalent antivenom (Aus pAV; $50 \mathrm{U} / \mathrm{mL}$ ) at the $\mathrm{t}_{90}$ time point on $B$. multicinctus venom $(3 \mu \mathrm{g} / \mathrm{mL})$ neurotoxicity. Panel (c) shows the effects on indirect twitches and panel (d) shows the effects on responses to ACh $(1 \mathrm{mM}), \mathrm{CCh}(20 \mu \mathrm{M})$ and $\mathrm{KCl}(40 \mathrm{mM})$, in the chick biventer cervicis nerve-muscle preparation. ${ }^{*} p<0.05$, significantly different compared to venom alone at $60 \mathrm{~min}$ (a) or compared to pre-venom response to same agonist at $180 \mathrm{~min}(\mathbf{b}, \mathbf{d}) .{ }^{+} p<0.05$, significantly different compared to response to agonist in the absence of antivenom or washing $(\mathbf{b}, \mathbf{d})$.

The addition of Chinese B. multicinctus antivenom $(60 \mathrm{U} / \mathrm{mL}, 10 \times$ the recommended titer), at the $t_{50}$ or $t_{20}$ time point after the addition of $B$. multicinctus venom $(3 \mu \mathrm{g} / \mathrm{mL})$, caused a significant delay in the time to abolish twitches (Figure 3a, Table 1), and significantly reversed the venom-induced inhibition of responses to ACh while having no significant effect on the responses to $\mathrm{CCh}$ or $\mathrm{KCl}$ (Figure $3 \mathrm{~b}$ ).

Table 1. Comparison of $t_{90}$ values for the neurotoxic effects of $B$. multicinctus venom in response to the addition of Chinese B. multicinctus antivenom or washing as indicated.

\begin{tabular}{cccccc}
\hline & Vehicle @ $\mathbf{t}_{\mathbf{9 0}}$ & $\mathbf{B m}$ AV @ $\mathbf{t}_{\mathbf{9 0}}$ & $\mathbf{B m}$ AV @ $\mathbf{t}_{\mathbf{5 0}}$ & $\mathbf{B m ~ A V ~} @ \mathbf{t}_{\mathbf{2 0}}$ & Washing @ $\mathbf{t}_{\mathbf{2 0}}$ \\
\hline $\mathrm{t}_{90}(\mathrm{~min})$ & $26.2 \pm 0.9$ & $28.0 \pm 1.2$ & $34.5 \pm 1.3^{\dagger}$ & $56.2 \pm 8.0^{*, \S}$ & $26.0 \pm 1.0^{\dagger}$ \\
\hline
\end{tabular}

Values are mean \pm SEM, $n=6 ;{ }^{*} p<0.05$ significantly different from $t_{90}$ (+vehicle) (one-way ANOVA). ${ }^{\S} p<0.05$ significantly different from $\mathrm{Bm} \mathrm{AV} \mathrm{t}_{90}$ addition (one-way ANOVA). ${ }^{\dagger} p<0.05$ significantly different from Bm AV $\mathrm{t}_{20}$ addition (unpaired $t$-test). 
Repeatedly washing the tissue, commencing at the $t_{20}$ time point after the addition of $B$. multicinctus venom $(3 \mu \mathrm{g} / \mathrm{mL})$, for $5 \mathrm{~s}$ every $1 \mathrm{~min}$ for $10 \mathrm{~min}$, and then for $5 \mathrm{~s}$ every $5 \mathrm{~min}$, did not produce any recovery of twitch height or delay in the time to abolish twitches (Figure 3a, Table 1) but did significantly reverse the venom-induced inhibition of responses to $\mathrm{ACh}$ (76 $\pm 4 \%$ of initial response). This had a minimal effect on the response to $\mathrm{CCh}$, and no significant effect on the response to $\mathrm{KCl}$ (Figure $3 \mathrm{~b}$ ).

Comparison of the $t_{90}$ values between venom alone, venom with Chinese $B$. multicinctus antivenom added at different time points, and venom with repeated washing, indicated that only antivenom addition at $t_{20}$ significantly prolonged the $t_{90}$ value compared to venom alone $(p<0.05$, Table 1$)$. There was no significant effect of washing commencing at $t_{20}$, or antivenom addition at $t_{50}$ or $t_{90}$.

The addition of Australian polyvalent antivenom $(50 \mathrm{U} / \mathrm{mL}, 166 \times$ the recommended titer), at the $t_{90}$ time point after the addition of $B$. multicinctus venom $(3 \mu \mathrm{g} / \mathrm{mL})$, did not restore the twitch height over a $180 \mathrm{~min}$ period (Figure 3c). However, the addition of Australian polyvalent antivenom significantly reversed the inhibition of responses to ACh while having no significant effect on the responses to $\mathrm{CCh}$ and $\mathrm{KCl}$ (Figure 3d).

\section{Discussion}

Chinese B. multicinctus venom caused concentration-dependent inhibition of nervemediated twitches in an in vitro skeletal muscle preparation. Contractile responses to nicotinic acetylcholine receptor agonists were attenuated indicating a postsynaptic site of action. Although it is worth noting that the effects of the potent, slower acting presynaptic neurotoxins, present in the venom, will be masked when examining whole venom. No evidence of myotoxicity was observed. The neurotoxic effects of the venom were almost completely abolished by the prior addition of $B$. multicinctus antivenom (at $2 \times$ the recommended titer) and an Australian polyvalent snake antivenom (50× the recommended titer). The latter is raised against a range of Australian elapid snakes (i.e., Acanthophis antarcticus, Notechis scutatus, Oxyuranus scutellatus, Pseudechis australis, and Pseudonaja textilis) but not $B$. multicinctus venom. Therefore, it seems as though both antivenoms recognize the post- and pre-synaptic neurotoxins found in B. multicinctus venom. This is not surprising as we have previously shown cross neutralization between Australian polyvalent snake antivenom and non-Australian snake species including the Chinese cobra, New Guinea small-eyed snake, monocled cobra, banded krait, common krait and king cobra [16-18]. The ability of other heterologous antivenoms to neutralize the neuromuscular effects of Bungarus genus venoms and toxins has also been reported previously [19-21].

In antivenom reversal studies, addition of either antivenom (i.e., Chinese B. multicinctus antivenom at $10 \times$ the recommended titer and Australian polyvalent antivenom at $166 \times$ the recommended titer), at the $t_{90}$ time point after venom, was unable to reverse the abolition of twitches. To examine this further, we tried adding the antivenom at earlier time points (i.e., $t_{20}$ and $t_{50}$ ). While neither of these strategies prevented the abolition of twitches, responses to the nicotinic receptor agonist ACh were partially restored in all instances, indicating that the post-synaptic effects of the venom were at least partially reversible. Additionally, when antivenom was added at the $t_{20}$ time point, there was a significant delay in the time taken to abolish twitches (based on a comparison of $t_{90}$ values) indicating further reversal of the post-synaptic effects, and potentially pre-synaptic effects. In contrast, repetitive washing commencing at the same time point (i.e., $\left.t_{20}\right)$ had no significant delaying effect on venom-induced neurotoxicity but did restore contractile responses to ACh indicating partial reversal of the post-synaptic activity of the venom but not presynaptic activity.

As a comparison, we have recently shown that the in vitro post- and pre-synaptic neurotoxic effects of venom from the Australian coastal taipan (Oxyuranus scutellatus), in the same skeletal muscle preparation, can be delineated by the addition of antivenom at different time points after venom [22]. In this previous study, Australian polyvalent antivenom was able to prevent the pre-synaptic activity of $O$. scutellatus venom when 
added $5 \mathrm{~min}$ after the venom. However, antivenom was not effective when added $30 \mathrm{~min}$ after the venom and only partially effective when added $15 \mathrm{~min}$ after venom [22]. As a comparison, addition of antivenom at the $t_{20}$ time point in the current study, equates to approximately $8 \mathrm{~min}$ after the venom. The lack of ability of antivenoms to reverse the effects of pre-synaptic $\beta$-neurotoxins is well established [23]. Given that B. multicinctus contains $\beta$-bungarotoxin, and the relatively irreversible long-chain $\alpha$-bungarotoxin, it appears as though the 'window' for reversing the neurotoxic effects of $B$. multicinctus is very short.

In vivo murine $\mathrm{LD}_{50}$ (i.e., the concentration of venom required to kill $50 \%$ of a population of mice, usually over a $24-48 \mathrm{~h}$ time period) studies are often used to determine venom lethality/toxicity, and antivenom neutralization activity. However, $\mathrm{LD}_{50}$ studies are unable to identify the toxins responsible for death and, if neurotoxins are involved, unable to identify the site of action of the neurotoxins given the fact that the venom may contain pre-, post-synaptic neurotoxins or both $[14,24,25]$. We used the chick biventer preparation, which contains both focally- and multiply-innervated skeletal muscle fibers, to examine B. multicinctus venom toxicity in vitro. This preparation enables the determination of the site of action of venoms/toxins, i.e., either at the pre-synaptic nerve terminal, post-synaptic nerve terminal or underlying skeletal muscle $[24,26]$. Pre-synaptic neurotoxins abolish nerve-evoked indirect twitches by interrupting release of acetylcholine from the nerve terminal $[23,24]$. While post-synaptic neurotoxins block the nerve-evoked twitches by blocking the interaction between the transmitter (i.e., acetylcholine) and the skeletal muscle $\mathrm{nAChR}[14,24]$. These two different sites of action can be distinguished by examining the effects of the venom on responses to exogenous nAChR agonists. Pre-synaptic toxins do not affect responses, while post-synaptic toxins inhibit responses. However, when studying whole venoms, the presence of post-synaptic neurotoxins will mask the presence of pre-synaptic toxins given their faster and downstream site of action. Based on venomics data, B. multicinctus venom contains pre-synaptic and post-synaptic neurotoxins, but lacks myotoxic components $[9,27,28]$. This profile is likely to explain the lack of effect of the venom on contractile responses to $\mathrm{KCl}$, which is used as a method of identifying toxins which directly affect the skeletal muscle at the end plate [26].

Clinical data from snakebites with primary pre-synaptic neurotoxins, such as kraits (Bungarus spp.) and taipans (Oxyuranus spp.) suggest that antivenom does not reverse established neurotoxicity, but early antivenom administration may be associated with decreased severity or even prevent neurotoxicity [25,29,30]. Post addition of Chinese B. multicinctus antivenom at earlier time points, i.e., $t_{20}$ or $t_{50}$, did delay the time to abolish twitches and significantly reversed the venom-induced inhibition of responses to ACh, indicating partial efficacy despite the onset of both 'irreversible' pre- and post-synaptic neurotoxicity. Interestingly, compared to $t_{20}$ antivenom addition, repeated washing commencing at $\mathrm{t}_{20}$ did not delay the time to abolish twitches.

Therefore, the results of our in vitro studies, using the chick biventer cervicis preparation, mirror the clinical effects of $B$. multicinctus envenoming, where respiratory failure is a key feature in spite of early administration of the B. multicinctus antivenom [5]. This supports the hypothesis that the antivenom resistant neurotoxicity is most likely due to the action of the PLA $2 \beta$-bungarotoxins [10-13]. However, despite the close alignment of the experimental data with clinical outcomes, the extrapolation of data from experimental studies, including the chick biventer preparation, should be treated with caution given the species differences that have been reported, although these largely pertain to the activity of the post-synaptic $\alpha$-neurotoxins [31-33].

A recent study examined the efficacy of $B$. multicinctus antivenom against isolated toxins (i.e., $\alpha-, \beta$ - and $\gamma$-bungarotoxins) from $B$. multicinctus venom using mice (i.e., an $\mathrm{LD}_{50}$ assay and determining $\mathrm{ED}_{50}$ values) [34]. These authors confirmed that $\beta$-bungarotoxin was the most 'lethal' component with $\mathrm{LD}_{50}$ values of $0.004 \mu \mathrm{g} / \mathrm{g}$ (i.p), $0.015 \mu \mathrm{g} / \mathrm{g}$ (i.m) and $0.007 \mu \mathrm{g} / \mathrm{g}$ (i.v.). Interestingly, an examination of the immunoreactivity of the antivenom, using ELISA, indicated that the antivenom showed good neutralizing capacity against the crude $B$. multicinctus venom but weak immunoreactivity against $\alpha$-and $\gamma$ - 
bungarotoxins [34]. In addition, the immunoreactivity of the antivenom was 2.5 times higher against the whole venom than $\beta$-bungarotoxin [34]. Therefore, even with early clinical administration, the antivenom is likely to display varying efficacy against key toxins.

\section{Conclusions}

We showed that Chinese B. multicinctus venom displays potent in vitro neurotoxicity which is attenuated by monovalent $B$. multicinctus antivenom and, also, an Australian polyvalent snake antivenom. Neither antivenom was able to reverse the venom-induced neurotoxicity. Given the seemingly irreversible nature of the neurotoxic effects of $B$. multicinctus venom, it would appear that early administration of the specific antivenom within a certain time window would be advantageous in the clinical setting.

\section{Materials and Methods}

\subsection{Venom and Antivenoms}

Freeze-dried B. multicinctus venom (Orientoxin Co., Ltd., Shandong, China) was dissolved in $0.05 \%(w / v)$ bovine serum albumin and stored at $-20{ }^{\circ} \mathrm{C}$ until required. Chinese B. multicinctus monovalent antivenom (Bm AV; Batch number: 2018/03/01; expiry date: 2021/03/19) was purchased from Shanghai Serum Biological Technology Co., Ltd. (Shanghai, China). Australian polyvalent snake antivenom (Aus pAV; Batch number: 055517501; expiry date: 04/2013) was purchased from Seqirus (Melbourne, Australia). According to the instructions from the manufacturer, 10,000 units of B. multicinctus neutralizes 5-6 mg of dried B. multicinctus venom. For the Australian polyvalent snake antivenom, 100 units of antivenom neutralizes $1 \mathrm{mg}$ of dried venom from the species of snake against which the antivenom has been raised (i.e., brown snake, death adder, mulga snake, taipan, tiger snake). One vial of Aus pAV contains a total of 40,000 units. The amount of each antivenom required to neutralize the in vitro neurotoxic effects of the venom was calculated based on the relative amount of the venom in the organ bath.

\subsection{Chemicals and Reagents}

The following chemicals and drugs were used in the experiments described in this manuscript: acetylcholine chloride (ACh; Sigma-Aldrich, St. Louis, MO, USA), carbamylcholine chloride (CCh; Sigma-Aldrich, St. Louis, MO, USA), d-tubocurarine chloride (d-TC; Sigma-Aldrich, St. Louis, MO, USA), potassium chloride (KCl, Ajax Finechem Pty. Ltd., Taren Point, Australia), bovine serum albumin (Sigma-Aldrich, St. Louis, MO, USA). All chemicals were dissolved or diluted in Milli-Q water unless otherwise stated.

\subsection{Chick Biventer Cervicis Nerve-Muscle Preparation}

As previously described by us [15,16,18], male chickens (aged 4-10 days) were euthanized by exsanguination following $\mathrm{CO}_{2}$ inhalation. Biventer cervicis nerve-muscle preparations were dissected and then mounted on wire tissue holders under $1 \mathrm{~g}$ resting tension in $5 \mathrm{~mL}$ organ baths. Tissues were maintained at $34{ }^{\circ} \mathrm{C}$, bubbled with $95 \% \mathrm{O}_{2}$ and $5 \% \mathrm{CO}_{2}$, in physiological salt solution (mM): $118.4 \mathrm{NaCl}, 4.7 \mathrm{KCl}, 1.2 \mathrm{MgSO}_{4}, 1.2 \mathrm{KH}_{2} \mathrm{PO}_{4}$, $2.5 \mathrm{CaCl}_{2}, 25 \mathrm{NaHCO}_{3}$ and 11.1 glucose. Indirect twitches (i.e., nerve-mediated) were evoked by stimulating the motor nerve $(0.1 \mathrm{~Hz} ; 0.2 \mathrm{~ms})$ at supramaximal voltage $(10-20 \mathrm{~V})$, using a stimulator. Selective stimulation of the nerve was confirmed by the abolishment of twitches by the addition of d-TC $(10 \mu \mathrm{M})$. Tissues were then repeatedly washed with physiological salt solution to restore twitch response to nerve stimulation. Contractile responses of the tissues to exogenous acetylcholine (ACh; $1 \mathrm{mM}$ for $30 \mathrm{~s}$ ), carbachol (CCh; $20 \mu \mathrm{M}$ for $60 \mathrm{~s}$ ) and $\mathrm{KCl}(40 \mathrm{mM}$ for $30 \mathrm{~s}$ ) were obtained in the absence of nerve stimulation. Nerve stimulation was then recommenced for at least $30 \mathrm{~min}$ before the addition of the venom or antivenom. To examine the ability of antivenom to neutralize venom induced neurotoxicity (i.e., neurotoxicity prevention study), tissues were equilibrated with antivenom for $10 \mathrm{~min}$ before venom was added. To determine the ability of antivenoms to 
reverse venom induced neurotoxicity (i.e., neurotoxicity reversal study), antivenom was added at $t_{90}$ (i.e., time at which the initial twitch height was inhibited by $90 \%$ ). The effect of earlier antivenom addition at $t_{20}$ or $t_{50}$ (i.e., time at which the initial twitch height was inhibited by $20 \%$ or $50 \%$ ) was assessed for Bm AV. To further examine the reversibility of the neurotoxicity, when the twitch height had reduced to the $t_{20}$ time point, the organ baths were repeatedly washed for $5 \mathrm{~s}$ every $1 \mathrm{~min}$ for $10 \mathrm{~min}$ and then washed for $5 \mathrm{~s}$ every $5 \mathrm{~min}$ until any recovery of twitches had plateaued or $3 \mathrm{~h}$. At the conclusion of each experiment, $\mathrm{ACh}, \mathrm{CCh}$ and $\mathrm{KCl}$ were re-added as above. Twitch responses and responses to exogenous agonists were measured via a Grass FT03 force displacement transducer and recorded on a PowerLab system (ADInstruments Pty Ltd., Bella Vista, NSW, Australia).

\subsection{Data Analysis}

As previously described by us $[15,16,18]$, the height of electrically evoked twitches in the chick biventer cervicis preparation were measured at regular time intervals and expressed as a percentage of the pre-venom twitch height. The time taken for $90 \%$ inhibition of the twitch response ( $t_{90}$ values) was used to compare the neurotoxic effect of $B$. multicinctus venom following the addition of antivenom at different post-venom time points or repeat washing. Post-venom contractile responses to $\mathrm{ACh}, \mathrm{CCh}$ and $\mathrm{KCl}$ were expressed as a percentage of their original responses. Comparison of the effects of $B$. multicinctus venom on twitch height was made using a one-way analysis of variance (ANOVA). Comparison of responses to exogenous agonists before and after the addition of $B$. multicinctus venom or vehicle was made using a Student's paired $t$-test. All ANOVAs were followed by a Bonferroni's multiple comparison post-hoc test. Data presented are in the form of mean \pm standard error of the mean (SEM) of n experiments. All data and statistical analyses were performed using PRISM 8.0.2 (GraphPad Software, San Diego, CA, USA, 2019). For all statistical tests, $p<0.05$ was considered statistically significant.

Author Contributions: Conceptualization, Q.L., G.K.I. and W.C.H.; methodology, Q.L., T.M.H. and W.C.H.; formal analysis, Q.L. and W.C.H.; investigation, Q.L. and Y.Z.N.; data curation and writingoriginal draft preparation, Q.L. and W.C.H.; writing-review and editing and supervision, G.K.I. and W.C.H.; funding acquisition, Q.L., G.K.I. and W.C.H.; project administration, G.K.I. and W.C.H. All authors have read and agreed to the published version of the manuscript.

Funding: This study was supported by an Australian National Health and Medical Research Council (NHMRC) Senior Research Fellowship (ID: 1061041) awarded to G.K.I., a NHMRC Centres for Research Excellence Grant (ID: 1110343) awarded to G.K.I. and W.C.H., and a 2016 Guangzhou Municipal University scientific research project Grant (ID: 1201620144) awarded to Q.L.

Institutional Review Board Statement: This study was conducted according to the NHMRC Australian Code for the Care and Use of Animals for Scientific Purposes and approved by the Monash University Animal Ethics Committee (MARP2; application 22575; approved 18 December 2019).

Informed Consent Statement: Not applicable.

Conflicts of Interest: The authors declare no conflict of interest. The funders had no role in the design of the study; in the collection, analyses, or interpretation of data; in the writing of the manuscript, or in the decision to publish the results.

\section{References}

1. Zhao, E.M. Snakes in China, 1st ed.; Anhui Science and Technology Publishing House: Hefei, China, 2006; pp. $290-293$.

2. Lan, H.; Chen, Y.C. Chinese Venomous Snake and Treatment of Snakebite, 1st ed.; Shanghai Scientific \& Technical Publishers: Shanghai, China, 2008; pp. 535-540.

3. Uetz, P.; Freed, P.; Hošek, J. (Eds.) 2020. Available online: http:/ /www.reptile-database.org (accessed on 20 August 2020).

4. Chan, J.C.; Cockram, C.S.; Buckley, T.; Young, K.; Kay, R.; Tomlinson, B. Evenoming by Bungarus multicinctus (many-banded krait) in Hong Kong. J. Trop. Med. Hyg. 1995, 98, 457-460. [PubMed]

5. Mao, Y.C.; Liu, P.Y.; Chiang, L.C.; Liao, S.C.; Su, H.Y.; Hsieh, S.Y.; Yang, C.C. Bungarus multicinctus multicinctus snakebite in Taiwan. Am. J. Trop. Med. Hyg. 2017, 96, 1497-1504. [CrossRef] [PubMed] 
6. 2018 Expert Consensus on China Snake-bites Rescue and Treatment. Chin. J. Emerg. Med. 2018, 27, 1315-1322. [CrossRef]

7. Nirthanan, S.; Gwee, M.C. Three-finger alpha-neurotoxins and the nicotinic acetylcholine receptor, forty years on. J. Pharmacol. Sci. 2004, 94, 1-17. [CrossRef] [PubMed]

8. Rowan, E.G. What does beta-bungarotoxin do at the neuromuscular junction? Toxicon 2001, 39, 107-118. [CrossRef]

9. Shan, L.L.; Gao, J.F.; Zhang, Y.X.; Shen, S.S.; He, Y.; Wang, J.; Ma, X.M.; Ji, X. Proteomic characterization and comparison of venoms from two elapid snakes (Bungarus multicinctus and Naja atra) from China. J. Proteom. 2016, 138, 83-94. [CrossRef]

10. Chang, C.C.; Lee, C.Y. Isolation of neurotoxins from the venom of Bungarus multicinctus and their modes of neuromuscular blocking action. Arch. Int. Pharm. Ther. 1963, 144, 241-257.

11. Dixon, R.W.; Harris, J.B. Nerve terminal damage by beta-bungarotoxin: Its clinical significance. Am. J. Pathol. 1999, 154, 447-455. [CrossRef]

12. Prasarnpun, S.; Walsh, J.; Awad, S.S.; Harris, J.B. Envenoming bites by kraits: The biological basis of treatment-resistant neuromuscular paralysis. Brain 2005, 128, 2987-2996. [CrossRef]

13. Prasarnpun, S.; Walsh, J.; Harris, J.B. Beta-bungarotoxin-induced depletion of synaptic vesicles at the mammalian neuromuscular junction. Neuropharmacology 2004, 47, 304-314. [CrossRef]

14. Barber, C.M.; Isbister, G.K.; Hodgson, W.C. Alpha neurotoxins. Toxicon 2013, 66, 47-58. [CrossRef] [PubMed]

15. Rusmili, M.R.; Yee, T.T.; Mustafa, M.R.; Othman, I.; Hodgson, W.C. In-vitro neurotoxicity of two Malaysian krait species (Bungarus candidus and Bungarus fasciatus) venoms: Neutralization by monovalent and polyvalent antivenoms from Thailand. Toxins 2014, 6, 1036-1048. [CrossRef] [PubMed]

16. Liang, Q.; Huynh, T.M.; Konstantakopoulos, N.; Isbister, G.K.; Hodgson, W.C. An examination of the neutralization of in vitro toxicity of Chinese cobra (Naja atra) venom by different antivenoms. Biomedicines 2020, 8, 377. [CrossRef]

17. Tibballs, J.; Kuruppu, S.; Hodgson, W.C.; Carroll, T.; Hawdon, G.; Sourial, M.; Baker, T.; Winkel, K. Cardiovascular, haematological and neurological effects of the venom of the Papuan New Guinean small-eyed snake (Micropechis ikaheka) and their neutralisation with CSL polyvalent and black snake antivenoms. Toxicon 2003, 42, 647-655. [CrossRef] [PubMed]

18. Silva, A.; Hodgson, W.C.; Isbister, G.K. Cross-neutralisation of in vitro neurotoxity of Asian and Australian snake neurotoxins and venoms by different antivenoms. Toxins 2016, 8, 302. [CrossRef]

19. Leong, P.K.; Tan, N.H.; Fung, S.Y.; Sim, S.M. Cross neutralisation of Southeast Asian cobra and krait venoms by Indian polyvalent antivenoms. Trans. R. Soc. Trop. Med. Hyg. 2012, 106, 731-737. [CrossRef]

20. Leong, P.K.; Sim, S.M.; Fung, S.Y.; Sumana, K.; Sitprija, V.; Tan, N.H. Cross neutralization of Afro-Asian cobra and Asian krait venoms by a Thai polyvalent snake antivenom (Neuro Polyvalent Snake Antivenom). PLoS Negl. Trop. Dis. 2012, 6, e1672. [CrossRef]

21. Oh, A.M.F.; Tan, C.H.; Tan, K.Y.; Quraishi, N.H.; Tan, N.H. Venom proteome of Bungarus sindanus (Sind krait) from Pakistan and in vivo cross-neutralization of toxicity using an Indian polyvalent antivenom. J. Proteom. 2019, 193, 243-254. [CrossRef]

22. Madhushani, U.; Isbister, G.K.; Tasoulis, T.; Hodgson, W.C.; Silva, A. In-vitro neutralization of the neurotoxicity of coastal taipan venom by Australian polyvalent antivenom: The window of opportunity. Toxins 2020, 12, 690. [CrossRef]

23. Kuruppu, S.; Smith, A.I.; Isbister, G.K.; Hodgson, W.C. Neurotoxins from Australo-Papuan elapids: A biochemical and pharmacological perpective. Crit. Rev. Toxicol. 2008, 38, 73-86. [CrossRef]

24. Hodgson, W.C.; Wickramaratna, J.C. In vitro neuromuscular activity of snake venoms. Clin. Exp. Pharmacol. Physiol. 2002, 29, 807-814. [CrossRef] [PubMed]

25. Silva, A.; Hodgson, W.C.; Isbister, G.K. Antivenom for neuromuscular paralysis resulting from snake envenoming. Toxins 2017, 9, 143. [CrossRef] [PubMed]

26. Harvey, A.L.; Barfaraz, A.; Thomson, E.; Faiz, A.; Preston, S.; Harris, J.B. Screening of snake venoms for neurotoxic and myotoxic effects using simple in vitro preparations from rodents and chicks. Toxicon 1994, 32, 257-265. [CrossRef]

27. Liu, C.C.; Lin, C.C.; Hsiao, Y.C.; Wang, P.J.; Yu, J.S. Proteomic characterization of six Taiwanese snake venoms: Identification of species-specific proteins and development of a SISCAPA-MRM assay for cobra venom factors. J. Proteom. 2018, 187, 59-68. [CrossRef] [PubMed]

28. Jiang, Y.; Li, Y.; Lee, W.; Xu, X.; Zhang, Y.; Zhao, R.; Zhang, Y.; Wang, W. Venom gland transcriptomes of two elapid snakes (Bungarus multicinctus and Naja atra) and evolution of toxin genes. BMC Genom. 2011, 12, 1. [CrossRef] [PubMed]

29. Hung, H.T.; Höjer, J.; Du, N.T. Clinical features of 60 consecutive ICU-treated patients envenomed by Bungarus multicinctus. Southeast. Asian J. Trop. Med. Public Health 2009, 40, 518-524. [PubMed]

30. Ha, T.H.; Höjer, J.; Trinh, X.K.; Nguyen, T.D. A controlled clinical trial of a novel antivenom in patients envenomed by Bungarus multicinctus. J. Med. Toxicol. 2010, 6, 393-397. [CrossRef]

31. Silva, A.; Cristofori-Armstrong, B.; Rash, L.D.; Hodgson, W.C.; Isbister, G.K. Defining the role of post-synaptic $\alpha$-neurotoxins in paralysis due to snake envenoming in humans. Cell Mol. Life Sci. 2018. [CrossRef]

32. Hart, A.J.; Isbister, G.K.; Hodgson, W.C. In vitro neurotoxic effects of Pseudechis spp. venoms: A comparison of avian and murine skeletal muscle preparations. Toxicon 2013, 63, 112-115. [CrossRef] 
33. Hart, A.J.; Isbister, G.K.; O’Donnell, P.; Williamson, N.A.; Hodgson, W.C. Species differences in the neuromuscular activity of post-synaptic neurotoxins from two Australian black snakes (Pseudechis porphyriacus and Pseudechis colletti). Toxicol. Lett. 2013, 219, 262-268. [CrossRef]

34. Lin, B.; Zhang, J.-R.; Lu, H.-J.; Zhao, L.; Chen, J.; Zhang, H.-F.; Wei, X.-S.; Zhang, L.-Y.; Wu, X.-B.; Lee, W.-H. Immunoreactivity and neutralization study of Chinese Bungarus multicinctus antivenin and lab-prepared anti-bungarotoxin antisera towards purified bungarotoxins and snake venoms. PLoS Negl. Trop. Dis. 2020, 14, e0008873. [CrossRef] [PubMed] 